\title{
Fluoride-Bridged $\left\{\mathrm{Gd}^{\mathrm{III}}{ }_{3} \mathrm{M}^{\mathrm{III}}{ }_{2}\right\}(\mathrm{M}=\mathrm{Cr}$, Fe, Ga) Molecular Coolers**
}

\author{
Kasper S. Pedersen, Giulia Lorusso, Juan José Morales, Thomas Weyhermüller, Stergios Piligkos, \\ Saurabh Kumar Singh, Dennis Larsen, Magnus Schau-Magnussen, Gopalan Rajaraman, Marco \\ Evangelisti,* Jesper Bendix*
}

Paramagnetic molecules with large spin and negligible magnetic anisotropy have received immense interests in the last few years due to the demonstration of large magneto-caloric effects (MCE). ${ }^{1}$ The effect is inherently related to the magnetic entropy increase at low temperatures, which follows an adiabatic demagnetization. Particularly, it is of interest to link the magnetic centers, and shield them magnetically from adjacent molecules, by lightweight ligands to furnish high magnetic density coolers. For an exchange-coupled polynuclear complex, if only the ground spin manifold, $S_{\mathrm{T}}$, is considered, the magnetic entropy is given by $S_{\mathrm{m}}=R \ln \left(2 S_{\mathrm{T}}+1\right)$. The type and strength of the magnetic interactions determine the way in which the entropy is gradually released with decreasing temperature, which occurs more abruptly in the temperature range where the interactions are important. ${ }^{\text {a, }, 2}$ Ultimately, on increasing the field change, $\Delta B$, the change of entropy, $-\Delta S_{\mathrm{m}}$, reaches its maximum value, corresponding to the full entropy content of the system, viz., the entropy sum over all single-ion spins, $S_{i}$, i.e., $R \sum_{i} \ln \left(2 S_{i}+1\right)$. Conclusively, it seems promising to combine $\mathrm{Gd}^{\mathrm{III}}\left(S_{\mathrm{Gd}}=7 / 2\right)$ with "magnetically isotropic" transition metal ions as $\mathrm{Cr}^{\mathrm{III}}\left(S_{\mathrm{Cr}}=3 / 2\right)$ or high-spin $\mathrm{Fe}^{\mathrm{III}}\left(S_{\mathrm{Fe}}=5 / 2\right)$, preferably connected by weak intramolecular ferromagnetic interactions. Recently, Winpenny and co-

[*] K. S. Pedersen, Dr. S. Piligkos, D. Larsen, M. SchauMagnussen, Prof. Dr. J. Bendix

Department of Chemistry

University of Copenhagen

Universitetsparken 5, DK-2100 Copenhagen, Denmark

Fax: (+45) 35320214

E-mail: bendix@kiku.dk (J.B.)

Dr. G. Lorusso, J. J. Morales, Dr. M. Evangelisti Instituto de Ciencia de Materiales de Aragón,

Departamento de Física de la Materia Condensada, CSICUniversidad de Zaragoza, 50009 Zaragoza, Spain

E-mail: evange@unizar.es (M.E.)

Dr. T. Weyhermüller

Max Planck Institute for Chemical Energy Conversion Mülheim an der Ruhr, Germany

S. K. Singh, Dr. G. Rajaraman

Department of Chemistry, Indian Institute of Technology Bombay, Powai, Mumbai, India

[**] K.S.P. and S.P. thank the Danish Ministry of Science Innovation and Higher Education for an EliteForsk travel grant and a Sapere Aude Fellowship (10-081659), respectively. G.L., J.J.M. and M.E. acknowledge financial support by the Spanish MINECO through grant MAT201238318-C03-01. G.L. is also grateful to EC for a Marie CurieIEF (PIEF-GA-2011-299356). G.R would like to thank DST, India (SR/S1/IC-41/2010; SR/NM/NS-1119/2011) for funding and IITB for HPC resources. workers, ${ }^{3}$ and we, ${ }^{4}$ reported the first examples of polynuclear complexes incorporating fluoride-bridged $\left\{\mathrm{Cr}{ }^{\mathrm{III}}-\mathrm{F}-\mathrm{Ln}^{\mathrm{III}}\right\}$ units. These systems owe their existence to the robust character of $\mathrm{Cr}^{\mathrm{III}}$ $\left(\mathrm{d}^{3}\right)$ complexes by avoiding precipitation of insoluble $\mathrm{LnF}_{3} .^{5}$ Unfortunately, this fact imposes strong limitations on the chemistry that can be exploited and we herein demonstrate that fluoridebridged 3d-4f polynuclear complexes can indeed also be prepared from labile transition metal fluoride complexes. As we recently communicated, the reaction of fac-[ $\left.\mathrm{CrF}_{3}\left(\mathrm{Me}_{3} \mathrm{tacn}\right)\right] \cdot 4 \mathrm{H}_{2} \mathrm{O}$ (Mestacn $=N, N^{\prime}, N^{\prime \prime}$-trimethyl-1,4,7-triazacyclononane) with $\mathrm{Nd}\left(\mathrm{NO}_{3}\right)_{3} \cdot 6 \mathrm{H}_{2} \mathrm{O}$ yields a fluoride-bridged $\left\{\mathrm{Nd}_{3} \mathrm{Cr}_{2}\right\}$ trigonal bipyramid (TBP). Performing the same reaction employing $\mathrm{Gd}\left(\mathrm{NO}_{3}\right)_{3} \cdot 5 \mathrm{H}_{2} \mathrm{O}$ affords the closely related $\left[\left\{\mathrm{CrF}_{3}(\mathrm{Me} 3 \mathrm{tacn})\right\}_{2} \mathrm{Gd}_{3} \mathrm{~F}_{2}\left(\mathrm{NO}_{3}\right)_{7}\left(\mathrm{H}_{2} \mathrm{O}\right)-\right.$ $\left.\left(\mathrm{CH}_{3} \mathrm{CN}\right)\right] \cdot 4 \mathrm{CH}_{3} \mathrm{CN}(\mathbf{1})$ which can be considered as a lightweight analog of the $\left[\left\{\mathrm{CrF}_{3}\left(\mathrm{Me}_{3} \text { tame) }\right\}_{2} \mathrm{Gd}_{3} \mathrm{~F}_{3}(\mathrm{hfac})_{6}\right] \cdot 7 \mathrm{CH}_{3} \mathrm{CN}\right.$ (Mestame $=$ 1,1,1-tris $\{$ (methylamino)methyl $\}$ ethane, $\mathrm{hfacH}=1,1,1,5,5,5-$ hexafluoro-acetylacetone) TBP-shaped pentanuclear system that exhibits good cooling properties. Although this result is unsurprising, the analogous reaction with novel fac$\left[\mathrm{FeF}_{3}(\mathrm{Me} 3 \mathrm{tacn})\right] \cdot \mathrm{H}_{2} \mathrm{O}$ and $\mathrm{fac}-\left[\mathrm{GaF}_{3}\left(\mathrm{Me}_{3} \mathrm{tacn}\right)\right] \cdot 4 \mathrm{H}_{2} \mathrm{O}$, conveniently synthesized from $\mathrm{FeF}_{3}$ and $\mathrm{GaF}_{3} \cdot 3 \mathrm{H}_{2} \mathrm{O}$, respectively, yield isostructural $\left.\quad\left\{\mathrm{MF}_{3}\left(\mathrm{Me}_{3} \mathrm{tacn}\right)\right\}_{2} \mathrm{Gd}_{3} \mathrm{~F}_{2}\left(\mathrm{NO}_{3}\right)_{7}\left(\mathrm{H}_{2} \mathrm{O}\right)\left(\mathrm{CH}_{3} \mathrm{CN}\right)\right]$. $4 \mathrm{CH}_{3} \mathrm{CN}(\mathrm{M}=\mathrm{Fe}(2)$, Ga (3); cf. Figure 1) without any signs of $\mathrm{GdF}_{3}$ formation. Notably, the presence of any hydroxide bridging can be safely ruled out based on electrospray mass spectra (Figures S4-6).

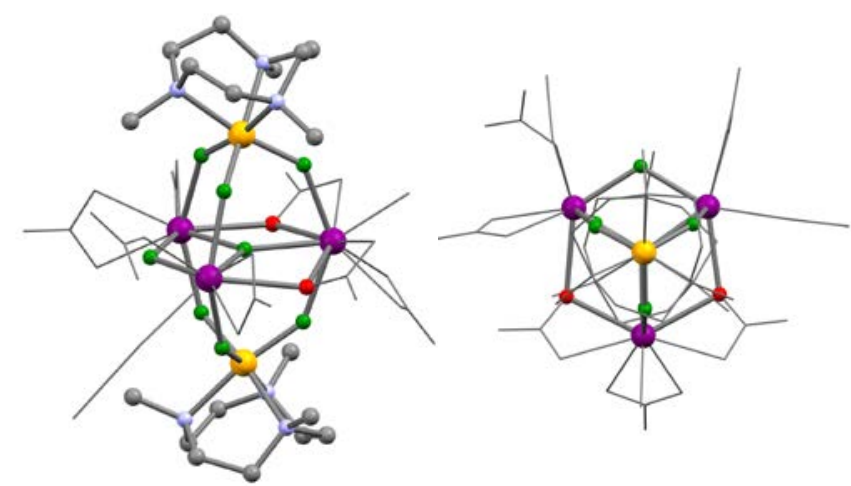

Figure 1. Structure of $\mathbf{2}$ shown in perspective (left) and along the $\mathrm{Fe} \cdots \mathrm{Fe}$ direction (right). Color codes: Gd, purple; Fe, orange; F, green; O, red; N, blue; $\mathrm{C}$, grey. For clarity, $\mathrm{CH}_{3} \mathrm{CN}$ molecules and the auxiliary $\mathrm{Gd}$ ligand sphere is shown as wireframe.

The capping fac-[FeF $\left.3\left(\mathrm{Me}_{3} \mathrm{tacn}\right)\right]$ units $\left(\angle \mathrm{Gd}-\mathrm{F}-\mathrm{Fe}=137.1(1)^{\circ}-\right.$ $\left.143.1(1)^{\circ}\right)$ impose an approximately isosceles $\left\{\mathrm{Gd}_{3}\right\}$ triangle. Herein, two edges consist of $\eta^{1}: \eta^{2}: \mu_{2}$-bridging nitrate ions and one edge consists of a $\mu_{2}$-fluoride (cf. Figure 1). Additionally, the center furnishes a single $\mu_{3}$-fluoride bridge close to the $\left\{\mathrm{Gd}_{3}\right\}$ plane with Gd- $\left(\mu_{3}-\mathrm{F}\right)-\mathrm{Gd}$ angles of $110.43(11)^{\circ}, 124.64(12)^{\circ}$ and $124.93(11)^{\circ}$. Compounds 2 and 3 add to the tiny family of fourth row/transition element-lanthanide, fluoride-bridged systems which, in addition to the $\mathrm{Cr}^{\mathrm{III}}$ systems, ${ }^{3,4}$ only encompasses $\left[\mathrm{La}\left\{\left(\mathrm{C}_{5} \mathrm{Me}_{4} \mathrm{Et}\right)_{2} \mathrm{Ti}_{2} \mathrm{~F}_{7}\right\}_{3}\right]$ and 
$\left[\mathrm{Ln}\left\{\left(\mathrm{C}_{5} \mathrm{Me}_{5}\right)_{2} \mathrm{Ti}_{2} \mathrm{~F}_{7}\right\}_{3}\right] \quad(\mathrm{Ln}=\mathrm{Pr}, \mathrm{Nd}) .{ }^{6}$ These latter systems, however, rely on the pronounced "hard" metal ions $\mathrm{Ti}^{\mathrm{IV}}$ and $\mathrm{Ln}^{\mathrm{III}}$, which compete efficiently for fluoride-abstraction. Neither $\mathrm{Fe}^{\mathrm{III}}$ nor $\mathrm{Ga}^{\mathrm{III}}$ are as "hard" as $\mathrm{Ti}^{\mathrm{IV}}$ or kinetically robust as $\mathrm{Cr}^{\mathrm{III}}$, but, surprisingly, exhibit similar reactivity towards $\mathrm{Gd}^{\mathrm{III}}$. The lightweight structures and the larger spin possessed by high-spin $\mathrm{Fe}^{\mathrm{III}}$ over $\mathrm{Cr}^{\mathrm{III}}$, fuelled our curiosity whether improved molecular coolers could result. The magnetic data for the isolated fac- $\left[\mathrm{CrF}_{3}\left(\mathrm{Me}_{3} \mathrm{tacn}\right)\right] \cdot 4 \mathrm{H}_{2} \mathrm{O}$ and fac-[ $\left[\mathrm{FeF}_{3}\left(\mathrm{Me}_{3} \mathrm{tacn}\right)\right] \cdot \mathrm{H}_{2} \mathrm{O}$ complexes are shown in the Supporting Information (Figure S7-8). As expected, the magnetic data are largely reminiscent of a Curie behaviour with temperatureindependent $\chi T$ products approaching the values expected for $S_{\mathrm{Cr}}=$ $3 / 2$ and $S_{\mathrm{Fe}}=5 / 2$, with a $g$-factor of $g \approx 2$. The temperature dependence of the magnetic susceptibility for $\mathbf{1}, \mathbf{2}$ and $\mathbf{3}$ is shown in Figure 2 in the form of $\chi T$ products. The field dependence of the magnetizations is given in Figure 2 (inset) and Figures S9-11. The high-temperature values of the $\chi T$ products $\left(\mathbf{1}: 27.3 \mathrm{~cm}^{3} \mathrm{~mol}^{-1} \mathrm{~K}, \mathbf{2}\right.$ : $33.3 \mathrm{~cm}^{3} \mathrm{~mol}^{-1} \mathrm{~K}$ and 3: $\left.23.6 \mathrm{~cm}^{3} \mathrm{~mol}^{-1} \mathrm{~K}\right)$ are in good agreement with the values expected for the spin-only contributions from the uncorrelated ions. On cooling, all $\chi T$ products increase to reach 36.6, 96.1 and $28.5 \mathrm{~cm}^{3} \mathrm{~mol}^{-1} \mathrm{~K}$ for $\mathbf{1}, 2$ and 3, respectively. This behavior suggests the presence of intra-complex ferromagnetic interactions for all compounds. The magnetic data were fitted by use of the Levenberg-Marquardt algorithm ${ }^{7}$ and by numerical diagonalization of the matrix representation of the isotropic spinHamiltonian (1):

$$
\hat{H}=g \mu_{\mathrm{B}} \mathbf{B} \cdot \sum_{i} \hat{\mathbf{S}}_{i}+J_{i j} \sum_{i, j>i} \hat{\mathbf{S}}_{i} \cdot \hat{\mathbf{S}}_{j}
$$

where the indices $i$ and $j$ run through the constitutive single-ions of each compound, $g$ is the single-ion $g$-factor, fixed to 2.0 for all ions, $\hat{\mathbf{S}}$ is a spin-operator and $J_{i j}$ is the isotropic exchange coupling parameter between the $i^{\text {th }}$ and $j^{\text {th }}$ centres. For $\mathbf{1}$ and $\mathbf{2}$, the $\chi T$ product and the low temperature variable field magnetization ( $M$ vs. $H$ ) data can be fitted using just two parameters, namely: $J_{\mathrm{M}-\mathrm{Gd}}$ and $J_{\mathrm{Gd}-\mathrm{Gd}}$, while fitting the $\chi T$ data against spin-Hamiltonian (1) results in strongly correlated parameters. The modeling of the magnetic data of $\mathbf{3}$ affords a good estimation of the Gd-Gd exchange interaction void of complicating, additional interactions. Simultaneous fitting of the $\chi T$ product and the $M$ vs. $H$ data yields $J_{\mathrm{Gd}-\mathrm{Gd}}=-0.028 \mathrm{~cm}^{-1}$. The best-fit curves are shown as solid lines in Figure 2 and in the SI.

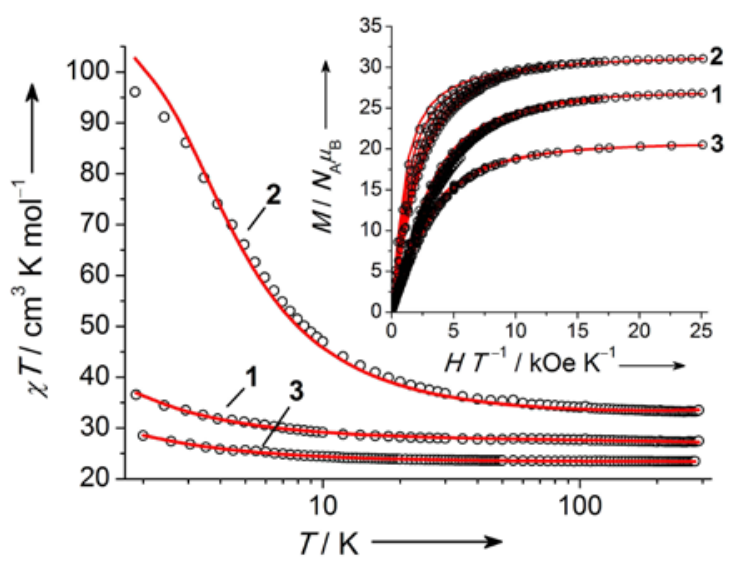

Figure 2. Temperature dependence of the $\chi T$ product $(\chi \equiv M / H, H=1000$ Oe) of 1-3. The solid, red lines are best-fits as described in the text. Insert: Reduced magnetization and best-fits for 1-3 at selected low temperatures.

The data of $\mathbf{1}$ and $\mathbf{2}$ were fitted with only $J_{\mathrm{M}-\mathrm{Gd}}$ as free parameter assuming transferability of $J_{\mathrm{Gd}-\mathrm{Gd}}$ from $\mathbf{3}$ to $\mathbf{1}$ and $\mathbf{2}$. For $\mathbf{1}$, this

yielded $J_{\mathrm{Cr}-\mathrm{Gd}}=-0.046 \mathrm{~cm}^{-1}$ and $-0.036 \mathrm{~cm}^{-1}$ as obtained from the $\chi T$ product and magnetization data, respectively. Analogously, for $\mathbf{2}$, the best-fit $J_{\mathrm{Fe}-\mathrm{Gd}}$ parameter values were $-0.25 \mathrm{~cm}^{-1}$ (from $\chi T$ ) and $-0.26 \mathrm{~cm}^{-1}$ (from $M$ vs. $H$ ).

In previous studies, ${ }^{8}$ we have established a magneto-structural correlation of the $J_{\mathrm{Cr}-\mathrm{Gd}}$ parameter as function of the $\mathrm{Cr}-\mathrm{F}-\mathrm{Gd}$ bridging angle. The average Cr-F-Gd bridging angle of $141.5^{\circ}$ in $\mathbf{1}$, should according to this correlation result in a very small positive $J_{\text {Cr-Gd. }}$ This is in reasonable agreement with the vanishing best-fit $J_{\mathrm{Cr}-\mathrm{Gd}}$ parameter value. To gain insight in the magnitude and sign of the $\mathrm{Fe}^{\mathrm{III}}-\mathrm{F}-\mathrm{Gd} \mathrm{III}^{\mathrm{II}}$ interaction, DFT calculations employing the experimental geometry were undertaken. The resulting parameter values are; $J_{\mathrm{Fe}-\mathrm{Gd}}=-0.35 \mathrm{~cm}^{-1}$ and $J_{\mathrm{Gd}-\mathrm{Gd}}=-0.02 \mathrm{~cm}^{-1}$, also in good agreement with the experimental findings and previous theoretical studies. ${ }^{9}$

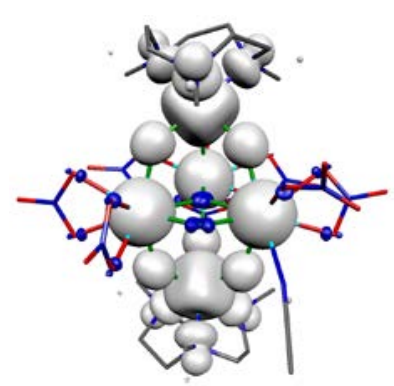

Figure 3. DFT-computed spin densities (left) for complex 2 drawn with isosurface value of $0.003 a_{0}^{-3}$ ( $a_{0}=$ Bohr length) and DFT-based magnetostructural correlations (right) developed for the model complex described in the text.

Further, we performed calculations on the dinuclear model $\left[\mathrm{Fe}^{\mathrm{III}} \mathrm{F}_{2}(\mathrm{py})_{4} \mathrm{Gd}^{\mathrm{III}}(\mathrm{hfac})_{4}\right]$ (py = pyridine) to develop a magnetostructural model for the Fe $\mathrm{F}^{\mathrm{III}}-\mathrm{F}-\mathrm{Gd}^{\mathrm{III}}$ unit mimicking our approach for the $\mathrm{Cr}^{\mathrm{III}}$ analog. ${ }^{8}$ This simple approach is justified by the equality of the average Fe-F (1.91 $\AA$ ) and $\mathrm{Cr}-\mathrm{F}(1.91 \AA)$ bond distances in $\mathbf{1}$ and 2. DFT calculations yield a ferromagnetic coupling $(J=-1.1$ $\mathrm{cm}^{-1}$ ) for the dinuclear model in contrast to the $\mathrm{Cr}$ III analog where an antiferromagnetic coupling was calculated. As discussed by Ruiz and co-workers, the interaction of the $3 \mathrm{~d}$ orbitals of transition metals with the $5 \mathrm{~d}$ orbitals of $\mathrm{Gd}^{\mathrm{III}}$ plays a key role in controlling the sign of the magnetic interaction. ${ }^{10}$ Previously, we established the mechanism of magnetic coupling for generic $3 d-\mathrm{Gd}^{\mathrm{III}}$ pairs where the crucial role of empty $5 \mathrm{~d}$ orbitals of $\mathrm{Gd}^{\mathrm{III}}$ was illustrated. ${ }^{11}$ Specifically, the occupation of $5 \mathrm{~d}$ orbitals is linked to the sign of the coupling constant, with larger occupation leading to more ferromagnetic interaction, in structurally related compounds. ${ }^{11 \mathrm{~b}}$ For $\mathrm{Cr}^{\mathrm{III}}$, with $\left(\mathrm{t}_{2 g}\right)^{3}$ configuration, interaction with $\mathrm{Gd}^{\mathrm{III}} 5 \mathrm{~d}$ orbitals is relatively smaller as compared to $\mathrm{Fe}^{\mathrm{III}}$ where the $\mathrm{e}_{g}$ orbitals promote stronger delocalization and interaction with the $\mathrm{Gd}^{\mathrm{III}} 5 \mathrm{~d}$ orbitals. The differential occupancy is evident also from the NBO calculations (see SI for details). The overlap between $3 \mathrm{~d}$ and $4 \mathrm{f}$ orbitals, which generally contributes to antiferromagnetic coupling, is also detected to be significantly less for the $\mathrm{Fe}^{\mathrm{III}}-\mathrm{Gd}^{\mathrm{III}}$ pair compared to $\mathrm{Cr}^{\mathrm{III}}-\mathrm{Gd}^{\mathrm{III}}$ analogues (cf. SI, Table S3). The angular dependence of $J_{\mathrm{Fe}-\mathrm{Gd}}$ in $\left\{\mathrm{Fe}^{\mathrm{III}}-\mathrm{F}-\mathrm{Gd}^{\mathrm{III}}\right\}$ (cf. Figure 3 (b)) shows the magnitude of the ferromagnetic $J_{\mathrm{Fe}-\mathrm{Gd}}$ to increase with the bridging angle, while for $\left\{\mathrm{Cr}^{\mathrm{III}}-\mathrm{F}-\mathrm{Gd}^{\mathrm{III}}\right\}$ an opposite trend was established. ${ }^{8}$ As the angle increases, the interaction of the $\mathrm{Fe}^{\mathrm{III}} \mathrm{d}_{\mathrm{z}^{2}}$ orbital with $\mathrm{Gd}^{\mathrm{III}} 5 \mathrm{~d}$ orbitals is expected to be large, leading to stronger ferromagnetic coupling 


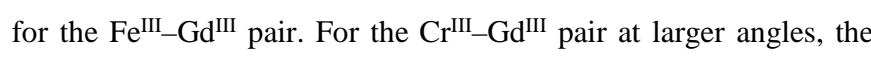
spin-bearing orbitals of $\mathrm{Cr}^{\text {III }}$ and the $\mathrm{Gd}^{\mathrm{III}} \mathrm{d}$-orbitals become orthogonal leading to a decrease in the interaction and less (more) ferromagnetic (antiferromagnetic) coupling. The spin density (cf. Figure 3 (a)) analysis reflects the points discussed where $\mathrm{Cr}^{\mathrm{III}}$ has gained spin density while there is significant reduction on the $\mathrm{Fe}^{\mathrm{III}}$ (3.09 vs. 4.28 for $\mathrm{Cr}^{\mathrm{III}}$ and $\mathrm{Fe}^{\mathrm{III}}$ respectively). This suggests a spinpolarization mechanism for the $\mathrm{Cr}{ }^{\mathrm{III}}-\mathrm{Gd}^{\mathrm{III}}$ unit and both spinpolarization and a delocalization mechanism operational for $\mathrm{Fe}^{\mathrm{III}}$ $\mathrm{Gd}^{\mathrm{III}}$. This is visually, directly observable in the significant departure from spherical shape of the spin-density distribution around $\mathrm{Fe}^{\mathrm{III}}$.

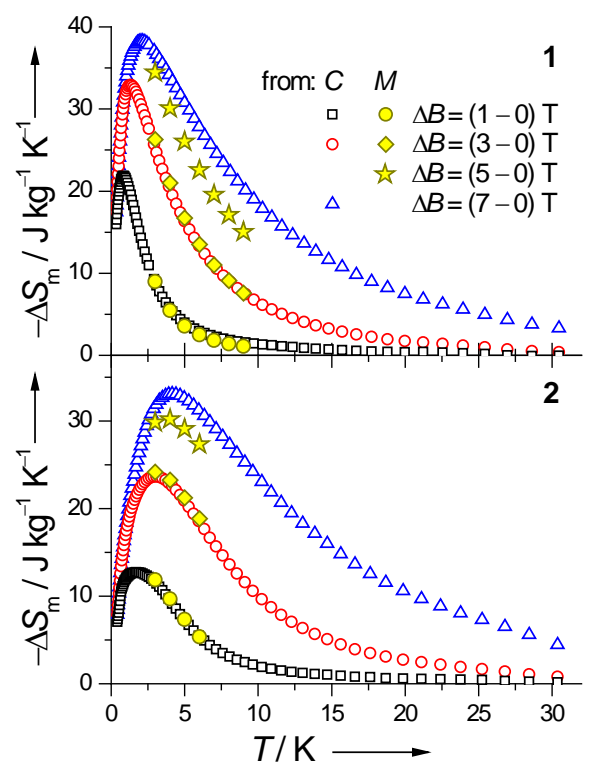

Figure 4. Magnetic entropy changes, $-\Delta S_{\mathrm{m}}$, corresponding to the labeled magnetic field changes, $\Delta B$, for $\mathbf{1}$ (top) and 2 (bottom), as obtained from specific heat, $C$, and magnetization, $M$, data. Cf. Figure S15 for a zoom of the low-temperature region.

The different magnitude of $J_{\mathrm{Cr}-\mathrm{Gd}}$ and $J_{\mathrm{Fe}-\mathrm{Gd}}$ is also evidenced in the experimental specific heat of $\mathbf{1}$ and $\mathbf{2}$, respectively, depicted in Figure S12 together with the calculated Schottky anomalies for the paramagnetic ions at the corresponding fields (solid lines). Indeed, while for $\mathbf{1}$ the intra-molecular magnetic interactions are already decoupled for fields larger than $\sim 1 \mathrm{~T}$, for 2 , fields larger than $\sim 7 \mathrm{~T}$ are necessary. A prominent feature in 2 is the kink at $T_{c}=0.65 \mathrm{~K}$ that we ascribe to a magnetic phase transition, driven by dipolar interactions. We notice that the magnetic entropy at $T_{c}$ amounts to about $\sim 3.2 k_{\mathrm{B}}$ per molecular spin (Figure S12), which is close to the value corresponding to the highest possible spin per molecule obtained in case of ferromagnetic alignment, i.e., $k_{\mathrm{B}} \ln \left(2 S_{\mathrm{T}}+1\right)=$ $3.47 k_{\mathrm{B}}$, where $S_{\mathrm{T}}=3 S_{\mathrm{Gd}}+2 S_{\mathrm{Fe}}=31 / 2$. Thus, we conjecture that the phase transition takes place concomitantly with the establishment of intra-molecular alignment of spins. Indeed, $T_{C}$ is of the same order as the dipolar interaction energy between nearest-neighbor $S_{\mathrm{T}}=31 / 2$ molecules, i.e., $\mu^{2} / r^{3} \approx 0.3 \mathrm{~K}$, where $r \approx 12 \AA$ is the inter-molecular distance. Contrary, $J_{\mathrm{Cr}-\mathrm{Gd}}$ in $\mathbf{1}$ is not sufficiently strong to compete with thermal fluctuations. Thus, neither an intra-molecular ordering nor a phase transition is observed for $\mathbf{1}$.

The MCE is evaluated by obtaining the isothermal magnetic entropy changes $-\Delta S_{\mathrm{m}}$ from the entropy data. We also use the magnetization data (Figures S9-12) for the same purpose by means of the Maxwell relation $\Delta S_{\mathrm{m}}(T)=\int[\partial M(T, B) / \partial T]_{B} \mathrm{~d} B$. From Figure 4 , we report that the maximum $-\Delta S_{\mathrm{m}}$ values for the largest $\Delta B$ (from
$7 \mathrm{~T}$ to $0 \mathrm{~T}$ ) are $38.3 \mathrm{~J} \mathrm{~kg}^{-1} \mathrm{~K}^{-1}(T=2.0 \mathrm{~K})$ and $33.1 \mathrm{~J} \mathrm{~kg}^{-1} \mathrm{~K}^{-1}(T=$ $4.2 \mathrm{~K}$ ) for 1 and 2 , respectively. The maximum entropy value involved, corresponding to $3 S_{\mathrm{Gd}}$ and $2 S_{\mathrm{Cr}}\left(\mathrm{S}_{\mathrm{Fe}}\right)$ is calculated as 43.4 (47.1) $\mathrm{J} \mathrm{kg}^{-1} \mathrm{~K}^{-1}$ for 1 (2). Therefore, for $\Delta B$ larger than the field needed to fully overwhelm the magnetic interactions involved, a larger $-\Delta S_{\mathrm{m}}$ should occur in $\mathbf{2}$ rather than $\mathbf{1}$. Otherwise, one would expect a larger $-\Delta S_{\mathrm{m}}$ in the case of weaker magnetic correlations, as experimentally observed for $\Delta B \leq 7 \mathrm{~T}$. Indeed, a weaker coupling promotes a relatively larger number of low-lying excited spin states, thus favoring a larger field-dependence of the MCE. Finally, we point out that the experimental $-\Delta S_{\mathrm{m}}$ of $\mathbf{1}$ is extremely large for a 3d-4f complex and comparable to the best magnetic molecular coolers at liquid-helium temperatures. ${ }^{12}$

In summary, a small family of unusual fourth-row metal ionlanthanide complexes with bridging fluoride ions is reported. The combination of lightweight auxiliary ligands and tunable interaction by choice of metal ion makes these systems interesting modules for low-temperature cooling applications.

Keywords: fluoride $\cdot$ magnetic refrigeration $\cdot$ lanthanides $\cdot$ magnetic properties · DFT

${ }^{1}$ a) M. Evangelisti, E. K. Brechin, Dalton Trans. 2010, 39, 4672; b) J. W. Sharples, D. Collison, Polyhedron 2013, 54, 91; c) M. Evangelisti in J. Bartolomé, F. Luis and J. F. Fernández (eds.), Molecular Magnets, NanoScience and Technology, Springer-Verlag, Berlin, Heidelberg, pp. 365387, (2014).

${ }^{2}$ M. Evangelisti, A. Candini, M. Affronte, E. Pasca, L. J. de Jongh, R. T. W. Scott, E. K. Brechin, Phys. Rev. B 2009, 79, 104414.

${ }^{3}$ A. McRobbie, A. R. Sarwar, S. Yeninas, H. Nowell, M. L. Baker, D. Allan, M. Luban, C. A. Muryn, R. G. Pritchard, R. Prozorov, G. Timco, F. Tuna, G. F. S. Whitehead, R. E. P. Winpenny, Chem. Commun. 2011, 47, 6251.

${ }^{4}$ a) J. Dreiser, K. S. Pedersen, C. Piamonteze, S. Rusponi, Z. Salman, Md. E. Ali, M. Schau-Magnussen, C. Aa. Thuesen, S. Piligkos, H. Weihe, H. Mutka, O. Waldmann, P. Oppeneer, J. Bendix, F. Nolting, H. Brune, Chem. Sci. 2012, 3, 1024; b) T. Birk, K. S. Pedersen, C. Aa. Thuesen, T. Weyhermüller, M. Schau-Magnussen, S. Piligkos, H. Weihe, S. Mossin, M. Evangelisti, J. Bendix, Inorg. Chem. 2012, 51, 5435; c) C. Aa. Thuesen, K. S. Pedersen, M. Schau-Magnussen, M. Evangelisti, J. Vibenholt, S. Piligkos, H. Weihe, J. Bendix, Dalton Trans. 2012, 41, 11284.

${ }^{5}$ J. Dreiser, K. S. Pedersen, T. Birk, M. Schau-Magnussen, C. Piamonteze, S. Rusponi, T. Weyhermüller, H. Brune, F. Nolting, J. Bendix, J. Phys. Chem. A 2012, 116, 7842.

${ }^{6}$ a) F. Perdih, A. Demsar, A. Pevec, S. Petricek, I. Leban, G. Giester, J. Sieler, H. W. Roesky, Polyhedron 2001, 20, 1967; b) A. Pevec, M. Mrak, A. Demsar, S. Petricek, H. W. Roesky, Polyhedron 2003, 22, 575.

${ }^{7}$ W. H. Press, S. A. Teukolsky W. T. Vetterling, B. P. Flannery, 1992 Numerical Recipes in C: The Art of Scientific Computing, Cambridge University Press, Cambridge, MA, $2^{\text {nd }}$ Ed.

${ }^{8}$ S. K. Singh, K. S. Pedersen, M. Sigrist, C. Aa. Thuesen, M. SchauMagnussen, S. Piligkos, H. Mutka, H. Weihe, G. Rajaraman, J. Bendix, Chem. Commun. 2013, 49, 5583.

${ }^{9}$ T. Rajeshkumar, S. K. Singh, G. Rajaraman, Polyhedron, 2013, 52, 1299.

${ }^{10}$ E. Cremades, S. Gómez-Coca, D. Aravena, S. Alvarez, E. Ruiz, J. Am. Chem. Soc. 2012, 134, 10532.

${ }^{11}$ a) S. K. Singh, N. K. Tibrewal, G. Rajaraman, Dalton Trans. 2011, 40, 10897; b) S. K. Singh, G. Rajaraman, Dalton Trans. 2013, 42, 3623; c) G. Rajaraman, F. Totti, A. Bencini, A. Caneschi, R. Sessoli, D. Gatteschi, Dalton Trans. 2009, 3153; d) J. Paulovic, F. Cimpoesu, M. Ferbinteanu, K. Hirao, J. Am. Chem. Soc. 2004, 126, 3321; e) T. Rajeshkumar and G. Rajaraman, Chem. Commun. 2012, 48, 7856.

${ }^{12}$ a) M. Evangelisti, O. Roubeau, E. Palacios, A. Camón, T. N. Hooper, E. K. Brechin, J. J. Alonso, Angew. Chem. Int. Ed. 2011, 50, 6606; b) Y.-Z. Zheng, E. M. Pineda, M. Helliwell, R. E. P. Winpenny, Chem. Eur. J. 2012, 18, 4161; c) Y.-Z. Zheng, M. Evangelisti, F. Tuna, R. E. P. Winpenny, J. Am. Chem. Soc. 2012, 134, 1057; d) S. Langley, N. Chilton, B. Moubaraki, T. Hooper, E. K. Brechin, M. Evangelisti, K. S. Murray, Chem. Sci. 2011, 2, 1166; e) J. W. Sharples, Y.-Z. Zheng, F. Tuna, E. J. L. McInnes, Chem. 
Commun. 2011, 47, 7650; f) J.-B. Peng, Q.-C. Zhang, X.-J. Kong, Y.-P. Ren, L.-S. Long, R.-B. Huang, L.-S. Zheng, Z. Zheng, Angew. Chem., Int. Ed. 2011, 50, 10649; g) J.-B. Peng, Q.-C. Zhang, X.-J. Kong, Y.-Z. Zheng, Y.-P. Ren, L-S. Long, R.-B. Huang, L.-S. Zheng, Z. Zheng, J. Am. Chem. Soc. 2012, 134, 3314; h) R. Sibille, T. Mazet, B. Malaman, M. François, Chem. Eur. J. 2012, 18, 12970; i) E. Colacio, J. Ruiz, G. Lorusso, E. K. Brechin, M. Evangelisti, Chem. Commun. 2013, 49, 3845; j) G. Lorusso, J. W. Sharples,

E. Palacios, O. Roubeau, E. K. Brechin, R. Sessoli, A. Rossin, F. Tuna, E. J.

L. McInnes, D. Collison, M. Evangelisti, Adv. Mater. 2013, doi: 10.1002/adma.201301997. 